\title{
Figurative Language, Mental Imagery and Pragmatics
}

\author{
Robyn Carston \\ Department of Linguistics \\ University College London
}

\begin{abstract}
Many people report experiencing mental imagery (visual, auditory and/or kinetic) when they comprehend verbal metaphors. The question whether imagery is merely an incidental side-effect of processes of metaphor understanding or plays a key role in comprehension remains unresolved, with diametrically opposed views expressed among psychologists, philosophers and literary theorists. I survey a wide array of evidence (behavioural and neurocognitive) concerning the activation and use of imagery in language processing generally and metaphor processing in particular. I conclude that mental imagery is not an essential component in the comprehension of language, whether literal or metaphorical, but it is often automatically activated in the minds of hearers or readers as a by-product of their linguistic and pragmatic processes. Writers may exploit this fact and enhance the impact of imagery by producing extended and/or creative metaphors, so that, although not essential, imagistic effects can be as significant as propositional cognitive effects.
\end{abstract}




\section{Introduction}

What role, if any, does mental imagery play in the understanding of metaphor? Despite subjective reports by many people that they experience imagery when they process metaphors and other figurative language, there is rather little serious discussion of this question in the academic disciplines that study these uses of language, and certainly no agreement among those who do.

Some psychologists think that imagery plays an essential role in an account of metaphor understanding, e.g., Gibbs \& Bogonovich (1999, p. 37) say "Metaphor theories must be amended to account for the prominence of imagery in metaphor use" and Sadoski \& Paivio (2001, p. 87) say "Novel metaphors in particular appear to need imagery for interpretation, especially vehicle imagery”. Among philosophers, Davidson's (1978) 'image' theory of metaphor has been hugely influential, his basic claims being that there is no such thing as a metaphorical 'meaning' (that is, a propositional content) and that when language is used metaphorically it functions more like a picture or a photograph and leads us to 'see' one thing (the topic) as another (the metaphor vehicle). Whether he intended this to entail the tokening in our minds of mental imagery is open to interpretation, but there are philosophers who insist that at least some cases of metaphor do require mental imaging: for instance, Green (2017) distinguishes two broad categories of metaphor, those that he labels 'image-permitting' metaphors and those that he maintains are 'imagedemanding', that is, metaphors whose understanding requires the construction of a mental image (and this is not restricted to visual imagery). Some poets and literary critics talk in a way that seems to virtually equate metaphor with visual images, e.g., "It [= poetry] always endeavours to make you continuously see a physical thing. ... Visual meanings can only 
be transferred by the new bowl of metaphor." (Hulme 1936, 134). This seems a somewhat loose use and one which does not necessarily implicate a distinctive form of imagistic (as opposed to propositional) representation in the mind. However, in a recent set of studies which are much informed by current scientific work on embodied cognition, the literary analyst Cave (2016) talks of the important role of "perceptual and kinesic simulations" in our responses to literary metaphors (and to other figurative uses of language). ${ }^{1}$

For others, in all of these disciplines, mental imagery is, at most, a tangential phenomenon, playing no important role in metaphor interpretation. Some of the most important current work in psychology on the processes of metaphor comprehension makes no mention of mental imagery (e.g., Glucksberg, 2001) and, more generally, the topic of mental imagery has had a chequered career in psychology, having been dismissed by the behaviourists as being of no scientific interest ("a pleasant fiction", according to J.B. Watson (1928, p. 76)). Among literary theorists, I.A Richards, argues against imagery playing any essential or even significant role in understanding metaphor: "We cannot too firmly recognise that how a figure of speech works has nothing necessarily to do with how any images, as copies or duplicates of sense perceptions, may, for reader or writer, be backing up his words. In special cases for certain readers they may come in ... we must put no assumption about their necessary presence into our general theory." (Richards 1936/95, p. 98). Among philosophers of language, there is a strong camp of 'propositional' theorists, most prominently H.P. Grice (1975)and John Searle (1979), whose accounts of metaphor omit any mention of mental imagery and for whom the understanding of a metaphor is explained entirely in terms of implicitly communicated propositions (conversational implicatures). It is notable too that in accounts of metaphor understanding in current linguistic and cognitive pragmatics, whether neo-Gricean or

\footnotetext{
1 The possible connections between consciously experienced mental imagery and the perceptual simulations posited by cognitive embodiment theorists are discussed in section 3 below.
} 
relevance-theoretic, there is virtually no mention of mental imagery, even in discussion of cases of new, creative and/or poetic metaphor. However, in Carston (2010), I made a start on addressing the imagery question within pragmatics, which is further developed in section 4 below (see also Wilson, in press).

The main aim of this paper is to establish mental imagery as a topic worthy of discussion in pragmatic-semantic theorising about metaphor and to draw out some of the dimensions of the topic. I will focus on two questions (really two sets of interrelated questions):

I. What is meant by 'mental imagery'? Are the authors mentioned above all talking about the same thing when they use the phrase? How does the phenomenal experience of mental imagery relate to current discussions in cognitive science about perceptual simulation and embodied mental representations?

II. How and where, if at all, might mental imagery enter into pragmatic theories of metaphor comprehension/interpretation? Is it merely an incidental by-product of the essential (inferential) processes of understanding, or does it play some more central role, either as an intended cognitive effect itself or as a vehicle for facilitating the derivation of cognitive effects?

The structure of the paper is as follows: In section 2, I introduce some examples of what are intuitively highly imagistic metaphorical uses of language and discuss what their authors are trying to achieve with them and how they would be analysed in current pragmatic theories. In section 3, an attempt is made to become clearer about what phenomenologically salient 'mental imagery' is, distinguishing it from perceptual images (percepts), and considering its relation to the representations that come from automatic perceptual simulation, on the one hand, and from deliberate task-oriented image 
generation, on the other. In section 4, the issue of what role mental images may play in metaphor understanding is addressed. Evidence collected by some cognitive psychologists in support of the view that mental imagery plays an essential role in understanding one kind of metaphor (so-called 'image' metaphors) is presented and assessed. The position finally taken is that consciously available imagery is merely a by-product of linguistic and pragmatic processes of language understanding, but one which can, nonetheless, sometimes have an impactful and memorable effect on an audience. I end with a brief summing up.

\section{2. 'Imagistic' metaphors and the question of mental imagery in pragmatics}

In order to focus the discussion, here are two cases of metaphor, one a short poem, the other from a piece of descriptive prose:

1. Cyclamen

They are white moths

With wings

Lifted

Over a dark water

In act to fly,

Yet stayed

By their frail images

In its mahogany depths

R.S. Thomas (1946) 
2. '... a heron launched itself from low ground to our south, a foldaway construction of struts and canvas, snapping and locking itself into shape just in time to keep airborne, ...'

R. Macfarlane (2013, pp.298-299)

These are both pretty good examples of what are informally and intuitively called 'image metaphors', so in (1), for instance, the flowers of the cyclamen are 'seen as' white moths. Note that, strictly speaking, (2) is not formally a metaphor but a juxtaposition of topic ('a heron') and vehicle ('a foldaway construction'), without an explicit copula. So I should say that, for the purposes of this paper, I am not going to be concerned to distinguish metaphors, similes (e.g., 'They are like white moths', adapting the opening line of (1)) and juxtapositions, ${ }^{2}$ as the issues concerning mental imagery are essentially the same in all three cases.

Both of these authors have chosen to characterize one physical thing (a cyclamen and a heron, respectively) by describing in some detail another entirely distinct physical thing (moths and a canvas construction, respectively). ${ }^{3}$ Why have they done this, what do they hope to achieve? I take it that they are trying to capture in language a personal experience, primarily a perceptual experience, but one that probably also has an emotional (affective) dimension, and that the best way they can find to do this is by giving a literal description of something else altogether. That is, they are not so much describing a flower

\footnotetext{
${ }^{2}$ See Camp (2008) on juxtapositions, focussing on the famous poem by Ezra Pound: In a Station of the Metro The apparition of these faces in the crowd: Petals on a wet, black bough.

${ }^{3}$ Note how different this is from the cases of metaphor discussed within the 'conceptual metaphor' framework, which involve a mapping from a concrete domain (the metaphor vehicle) onto an abstract domain (the metaphor target), e.g. LIFE IS A JOURNEY, TIME IS SPACE, THE MIND IS A CONTAINER, a key claim being that the abstract concept can only be understood in terms of the concrete one (Lakoff, 1993; Gibbs, 1994).
} 
or a bird as describing/expressing something about the impact of that thing on their senses, the quality of that perceptual experience, and how it made them feel. The fineness of grain of perceptual experience typically outstrips the conceptual capacities of the perceiver (and, a fortiori, her powers of literal linguistic expression): we can perceptually discriminate many more colors, shapes, sounds, textures, movements, feelings, and moods than we have concepts or words for (see discussion in Bermúdez \& Cahen, 2015). It is, therefore, intrinsically very difficult, perhaps impossible, to give full expression to perceptual experience in the medium of words, but that is the challenge that the writers in (1) and (2) have set themselves: to use language in such a way as to adequately express their experience and so share it with others who were not present with them at the time. ${ }^{4}$

Sharing the experience with someone physically present at the time might have been achievable by simply pointing or by using a demonstrative, e.g., 'Look at that', (probably accompanied by directive eye gaze and expressive facial signals), and then relying on the addressee's own perceptual capacities. These are acts of ostensive communication that direct the addressee to attend to something in the external world. An interesting idea in the philosophical literature about how metaphor works is that it too has a demonstrative component. In the following passage, Elizabeth Camp exemplifies this idea with a metaphorical use whose 'imagistic' quality is auditory ('The drunk at the bar is a wheezing bagpipe') rather than the more prevalent visual case, to which the idea she discusses, of course, equally applies:

\footnotetext{
${ }^{4}$ The struggle to give verbal expression to intense personal experience is described vividly by the poet Ezra Pound recalling his experience of seeing faces in the metro station (see footnote 2 above): 'Three years ago in Paris I got out of a "metro" train at La Concorde, and saw suddenly a beautiful face, and then another and another, and then a beautiful child's face, and then another beautiful woman, and I tried all that day to find words for what this had meant to me, and I could not find any words that seemed to me worthy, or as lovely as that sudden emotion. ... I was still trying and I found, suddenly, the expression. I do not mean that I found words, but there came an equation ... not in speech, but in little splotches of colour ...' (Pound, 1970 [1914]: 86-87). For a discussion of the use of 'image-demanding' metaphors in the expression of personal experience (i.e. in self-expression), see Green (2017).
} 
"The fact that any given language contains only a finite number of fixed linguistic expressions constrains the range of properties its speakers can talk about directly. Demonstratives extend these linguistic resources significantly, by enabling speakers to exploit the world itself in order to construct novel expressions. Metaphors can function communicatively much like demonstratives in this respect. For example, characterizing the drunk at the bar as a "wheezing bagpipe" allows me to capture the particular tone of his voice: loud, braying, continuous, nasal. These latter adjectives provide you with a general schema for imagining the relevant sound, but the metaphor is considerably more vivid and precise, because it exploits your specific, experiential knowledge of the sound that bagpipes make."

(Camp, 2006, 10; italics added)

Camp does not talk explicitly here of mental images, but her analogy with demonstratives ('this', 'that', etc.) is highly suggestive in this regard. The use of a demonstrative in faceto-face communication involves 'ostending/showing' the addressee something in the external environment, thus inviting him to have a particular perceptual experience. The metaphorical case, on the other hand, invites the audience/reader to have a 'quasiperceptual' (i.e., imagistic) experience, one that depends on, not his current perceptual activity but, his memory (hence past perceptual experience) of, in her example, the sound of bagpipes. Returning to the 'heron' example in (2) above, we might not ourselves have seen exactly the kind of foldaway structure of canvas and struts an image of which the writer has in his mind; we can, however, use our memory of similar kinds of objects or their parts (e.g., a tent made of canvas, with poles that can snap into position), together with a degree of imaginative reconstruction, to supply a more or less complete image which informs our understanding of how the heron looked as it took flight. 
In his treatment of metaphor, Andrew Ortony (1975) begins with a discussion of the difficulty of giving verbal expression to perceptual and emotional experience. He talks of the "continuity of experience ... not just a temporal continuity, [but] a continuity in 'referential' space" and says "it is the total continuity of experience which at once underlies and necessitates the use of metaphor in linguistic communication" (ibid: 46). He maintains that the discrete digital nature of the symbol systems of language and logic, used literally, are, inevitably, incapable of capturing all the aspects of experience that we might want to describe, but that using language metaphorically can transcend these limitations.

According to Ortony, all normal instances of successful language comprehension involve processes of "particularization", that is, of hearers/readers "filling in the details between the linguistic signposts", by selecting relevant items from their rich store of background and contextual knowledge. ${ }^{5}$ He calls this "the language comprehender's digital-to-analog converter", which "takes him nearer to the continuous mode of perceived experience by taking him further away from the discrete mode of linguistic symbols" (ibid, p. 47). What is special about metaphor, he says, is that it greatly enhances this process of particularization, because 'it enables large 'chunks' to be converted or transferred; metaphor constrains and directs particularization” (ibid, p. 47). By 'large chunks', he appears to mean a dense mass of features or characteristics stored in the mind of the addressee and made accessible (activated) by the literal language of the metaphorical vehicle. So, for instance, in discussing the simile 'The thought slipped my mind like a squirrel behind a tree', he suggests that such characteristics as being ungraspable, sudden, elusive, briefly glimpsed, camouflaged, here one moment, gone the

\footnotetext{
5 This seems very much akin to both processes of 'pragmatic enrichment' of linguistically encoded meaning, as described in relevance theory (Sperber \& Wilson 1986/95; Carston 2002), and John Seale's concept of the Background, without which sentence meaning cannot determine a complete content (Searle 1980).
} 
next, are among the many features of our recalled experience of seeing squirrels slipping behind trees which may be applied to the quite different 'slipping' of a thought from a person's mind. As he says, it is difficult to find appropriate words to describe these features and many are themselves still metaphorical when predicated of a thought. Explaining further the nature of these chunks that metaphors can transfer from vehicle to topic, he says they are best thought of "as being a continuum of cognitive and perceptual characteristics with a few slices removed ${ }^{6}$ rather than as a list of discrete attributes", that is, as "nondiscretized, coherent, chunks of characteristics ... [which are] predicated en masse" (ibid, p. 50).

Ortony comes tantalizingly close in that paper to saying that the chunks of continuous information are 'mental images', or at least are abstracted from mental images, which are activated by the literal metaphor vehicle and are relevantly applicable to the metaphor topic, but he doesn't explicitly say this. In a later paper, though, in which the focus is on the expression of emotional states through metaphor, Fainsilber and Ortony (1987, p. 241) do make this connection: “... metaphors may help capture the vividness of phenomenal experience ... metaphors convey chunks of information rather than discrete units ... to say that 'Love is like a red, red rose' is likely to conjure up perceptual and sensory images in the listener, and in so doing is likely to better reflect the vividness of that which is to be communicated" (italics added).

The questions now are whether, and, if so, how pragmatic theories of metaphor understanding accommodate the kind of effects described above. More specifically, do these theories have a place for sensory-perceptual (and affective) experience, whether recalled, reconstructed or imagined, in their accounts of how people mentally process and interpret metaphorically used language? As noted in the Introduction, inferential

\footnotetext{
${ }^{6}$ I take it that among the 'slices removed' in this example might be such features as the colour and shape of the squirrel, which are not relevant to the metaphor topic.
} 
'propositional' accounts, such as Grice (1975) and Searle (1979), seem to have no such place. For Grice, the speaker of a metaphorical utterance does not mean what she says, but communicates her meaning indirectly as one or more conversational implicatures, that is, propositional entities, whose derivation can be 'rationally reconstructed' by an inferential process employing his conversational maxims and the guiding presumption that the speaker/writer is obeying the Co-operative Principle (Grice 1975). Searle's propositionalism is even more clearly put: "In the case of literal utterance, speaker's meaning and sentence meaning are the same; ... But, in the case of the metaphorical utterance, the truth conditions of the assertion are not determined by the truth conditions of the sentence ... [The hearer] must have some other principles ... that enable him to figure out that when the speaker says, 'S is $\mathrm{P}$ ', he means ' $\mathrm{S}$ is R' (Searle, 1979, pp. 84-86), and Searle's main concern is to delineate the principles by which the hearer derives a correct value for 'R' (e.g., for an utterance of 'Sally is a block of ice', 'R' might be 'emotionally cold and unresponsive').

On the orthodox relevance-theoretic (RT) account (Sperber \& Wilson, 2008), metaphorical uses communicate both explicatures and implicatures, that is, propositions ${ }^{7}$ communicated explicitly and implicitly, respectively. Consider what the implicatures communicated by the poem 'Cyclamen' in (1) above might be:

3. a. The cyclamen flowers look like the wings of white moths hovering over dark water.

b. The cyclamen petals are fluttering, thin, fragile, pale against a dark background.

\footnotetext{
${ }^{7}$ Sperber and Wilson $(1986 / 95,2008)$ tend to talk of 'assumptions' rather than propositions and others talk of 'thoughts' (e.g. Carston, 2002), but in any case, these are all understood to be amodal truth-evaluable conceptual representations.
} 
The first of these seems to be strongly communicated and the others (I take the suggestion in (3b) to constitute several distinct implicatures) are weaker, in that they are less determinate, that is, there is room for differences in interpretation, so someone else might infer that the petals are layered and clustered together, pointing upwards, each one like a mirror of another. (The relevance-theoretic concepts of 'weak implicature' and of 'weak communication', more generally, are discussed in section 4 below). Clearly, much of the 'content' and impact of the poem is lost here. That could be attributed to the inadequacy of my rendering of the implicated meaning, but, as virtually everyone working on metaphor concedes, attempts to give paraphrases of the 'meaning' communicated by metaphors are almost always inadequate, even when, as often occurs, they include further metaphorically used expressions (as in the 'squirrel/thought' example discussed above).

It is even more problematic to explain what the (alleged) explicature of 'Cyclamen' might be. On an orthodox relevance-theoretic account, a metaphorically used word is treated like other cases of loose use of language, that is, the lexically encoded concept is pragmatically adjusted so as to express a concept which could be applicable to the metaphor's topic. This is known as an 'ad hoc concept' and it is a constituent of the explicature of the utterance, replacing the lexical concept from which it was derived. To take a simple case, in grasping the intended meaning of the word 'chameleon' in the utterance 'Mary is a chameleon', the lexically encoded concept CHAMELEON (which denotes a certain kind of lizard known for its ability to change its skin colour) is pragmatically broadened. This adjustment of lexical meaning occurs as part of a relevance-driven inferential process that ensures that the explicature warrants implicatures about Mary, such as that she is fickle and untrustworthy, says different things in different circumstances depending on who she is trying to impress, etc. The result is an ad hoc concept (or occasion-specific sense) CHAMELEON* whose denotation includes both the 
colour-changing lizards and human beings with the relevant behavioural characteristics. (For detailed accounts of the processes involved, see Wilson and Carston, 2007, 2008; Sperber and Wilson, 2008).

How plausible would this account be in explaining the 'Cyclamen' poem (or the description of the 'heron' in (2), or the poem 'In a station of the metro' in footnote 2)? Do we infer a sequence of ad hoc concepts: MOTHS* (whose denotation includes actual moths and an array of other things that physically resemble moths, including certain flowers like cyclamens); WINGS* (whose denotation includes actual moth wings and other things whose physical appearance and movement is similar, including the petals of (some) cyclamens); LIFTED*, WATER*, FLY*, and so on? Virtually every substantive word in the poem after 'They are' would have to be pragmatically adjusted, which seems not only highly implausible as a means of understanding this poem, but also counter-productive, given that the literal meanings of the words used in this extended metaphor work together in describing a coherent scenario in which white moths are fluttering above dark water (and so on), a scenario which could not be recovered if the sequential online processing system was engaged in altering the meaning of the words. Perhaps, instead, it is a single (structurally complex) ad hoc concept, involving the whole predicate: [[[WHITE MOTHS [[WITH WINGS LIFTED] [OVER A DARK WATER]] ...]]]]*. What this phrasal ad hoc concept might be, what its denotation is (allegedly a broadening of the complex literal phrasal concept) is hard to say, if the question makes any sense at all. Ad hoc concepts just seem to be the wrong currency to capture the way in which the metaphors in (1) and (2) are understood.

I have argued elsewhere that, although the ad hoc concept account works for a wide range of simple lexical cases, there are others (typically, those that are novel, creative and/or extended) whose interpretation is better explained by a different mental 
processing route. On this mode of processing, there is no move to a broadened ad hoc concept that represents the metaphorical meaning, but, rather, the literal meaning of the metaphor vehicle (and the imagery it triggers) is maintained as a whole, providing the basis for a slower, more reflective inferential pragmatic process that selects implications from the literal meaning that can apply to the metaphor topic (Carston, 2010; Carston \& Wearing, 2011; see also Giora (2003) on the retention of literal meaning in metaphor comprehension.) On that account, mental images evoked by the literal meaning of the metaphor vehicle are phenomenologically salient by virtue of the slower, more sustained processing of the literal meaning. There seems to be some support for this account from empirical neurocognitive results on language processing, to be discussed in sections 3 and 4.

For many metaphors, judging them to be true or false seems beside the point. It may be reasonable to respond to familiar lexical metaphors like 'John is a mouse/bulldozer/chameleon ...' with 'No, he's not; he's really a lively/sensitive/reliable guy, when you get to know him', thereby apparently contradicting a component of the metaphorical meaning (that John is timid/insensitive/fickle, respectively). The fact that this kind of discussion can sensibly take place is often seen as supporting the ad hoc concept account as it indicates that the metaphorical meaning is incorporated into the explicature, that is, it is a constituent of the truth-conditional content of the utterance. However, this hardly arises for the 'image metaphors' under discussion; it would be bizarre for someone to express factual disagreement with the poet's description of the cyclamen, or for someone to say 'No, you are incorrect about the heron's flight'. The metaphors here are expressing a subjective experience, which is not open to denial by someone else. Rather, these metaphors are assessed for 'aptness' or felicitousness, for how well they capture an experience, for how insightful they are, for how effective they are 
(see Green (2017) on 'metaphorical banter', where apparent disagreements with someone's metaphorical utterance are shown to be disputes about aptness rather than truth). Literary critics tend to assess how 'good' metaphors or similes are, not whether they are true or false, and this 'goodness' judgement may be influenced by the mental images the metaphor evokes.

Assuming that phenomenologically salient mental images are evoked by metaphors, such as those in (1) and (2), a key question is whether this imagery is essential in understanding the metaphor or is, rather, merely a (pleasurable) side-effect or an epiphenomenon. In this regard, consider a discussion by Crisp (1996) of the following poem:

4. Autumn

A touch of cold in the Autumn night -

I walked abroad,

And saw the ruddy moon lean over a hedge

Like a red-faced farmer.

I did not stop to speak, but nodded,

And round about were the wistful stars

With white faces like town children.

T. E. Hulme (1909)

Crisp notes: “... it is the experience of this projection [of the image of a farmer's face onto the image of the moon] that excites and not the grasping of the banal proposition that the moon on a certain occasion was roundish and reddish. What motivates the projection, a similarity of shape and hue, is just that, a motivation. It sparks off an experience, that of 
seeing the roundish, reddish moon as a roundish, reddish farmer's face, that seems fundamentally non-propositional in nature.” (ibid, p. 84)

Crisp seems to be suggesting that mental imagery is essential in understanding this metaphor, that, without it, the point of the metaphor, the effects sought by the writer, would not be achievable. I come back to this issue in section 4 . The more general question is how the experience of mental images that many, if not all, people have when understanding at least some metaphorical uses of language should be located within semantic-pragmatic accounts of metaphor understanding. Of particular interest are (a) whether or not the evocation of imagery in the audience is intended by speakers/writers and (b) how it interacts with cognitive effects of a propositional sort. These questions are addressed in section 4, but before that, in the next section, I attempt to clarify the notion of 'mental imagery' that is at issue here.

\section{Mental images and perceptual simulations}

Mental imagery is something that people are aware of, that they experience (sometimes vividly) and can report on, although there seems to be considerable individual variation, both in the frequency of the experience and its vividness (Pecher et al., 2009). I take it, therefore, that it is a real phenomenon, as do all those involved in the debate about its role in metaphor understanding, including those who don't think it plays any significant role in understanding (see Kosslyn et al. (2006) for extended argument and evidence for the existence of mental imagery). So the task at hand is to pin down what it is and ensure that those who express different views on its significance in the understanding of metaphor are all talking about essentially the same thing. 
Starting with the obvious: mental imagery is distinct from perception. Mental imagery is often described as a 'quasi-sensory or quasi-perceptual experience' and as having similar phenomenal character to perceiving. As Nanay (2015, p. 1) says, "Seeing and visualizing [one kind of mental imaging $(\mathrm{RC})$ ] have very similar phenomenal character. If I visualize a red apple and if I see one, the phenomenal character of my experience will be very similar", 8 and yet we seldom mistake one for the other. The key difference, of course, is that mental imaging occurs in the absence of the stimulus conditions that are the cause of actual perceptual experience; it is something that we recognise as coming from memory or imagination (or dreaming). A second difference is that while perceiving is mandatory and involuntary (“you can’t help seeing a visual array as consisting of objects distributed in three-dimensional space” (Fodor, 1983, p. 53)), mental imaging is, in important respects, under voluntary control (it can be activated and, to some extent at least, de-activated by the will).

In an extensive study of mental imaging ('mindsight', as he calls it), McGinn (2004) sets out what he calls an 'imagination spectrum', starting from the percept through to full-blown creative imagining (ibid, p. 159). I reproduce here the part of the spectrum that is relevant to this discussion:

$$
\begin{aligned}
& \text { Percept }- \text { - - memory image }>\text { imaginative sensing }>\text { productive image }> \\
& \text { daydream } / \text { dream }>\ldots
\end{aligned}
$$

The percept, which is the impact of the world on our senses, is the starting point but, "being untainted by imagination", it is not really on the spectrum, hence the broken line,

\footnotetext{
8 According to one group of philosophers, the phenomenal similarity between perception and mental imagery is explained by the fact that the content of the two mental states is the same, e.g., the content of a percept of a red apple and the content of a mental image of a red apple are both some set of properties (perhaps redness, roundness, a particular size, edibleness, ...). (Currie \& Ravenscroft, 2002; Nanay, 2015).
} 
which indicates the transition to the image proper. The "memory image", although derived from the percept, should not be thought of as a kind of (degraded) percept, but rather as a distinct kind of mental entity, transformed by the workings of memory, which is selective and reconstructive (ibid, p. 35). The move to "imaginative sensing" involves the combination of percept and image: a current percept evokes a memory image, and the two coalesce into an instance of "seeing as" (e.g., seeing a bare three-sided figure as "a triangular hole, as a solid, as a geometrical drawing; as standing on its base, as hanging from its apex; as a mountain, as a wedge, as an arrow or pointer, ...” (ibid, p. 48)). Then, at the next stage on the spectrum, that of the "productive image", there is creative recombination of elements, marking a further move away from the strictly sensory. "Now we can generate novel images at will, rearranging the world as we see fit; we are no longer a slave to the actual." (ibid, p. 161). All three of these elements of McGinn's spectrum are of potential relevance in language use, including, in particular, metaphorical language (both its production and its comprehension). Memory images are likely to be stored in the encyclopaedic entries associated with linguistically encoded concepts (e.g., the concepts encoded by 'heron', 'cyclamen', 'moth', 'drunk (person)', 'bagpipe') and so may be activated in the process of linguistic decoding along with propositional knowledge about the denotations of the words. The concept of 'imaginative sensing' could apply to the perceptual experience of the authors of the metaphors discussed above (or at least their subsequent imag(in)ing of it): seeing the cyclamen flower and imag(in)ing it as a group of moths; seeing the heron taking flight and imag(in)ing it as a foldaway canvas-and-struts construct; hearing the drunk at the bar and imag(in)ing his voice as a wheezing bagpipe. For the reader/hearer of the metaphor, the imaging process might be better thought of in terms of McGinn's productive image, in that there is a (language-guided) interaction of two memory images, e.g., the image of pale moths against a dark background, which is 
composed from memory images activated by the words used but requires an active process of construction and combination, and which is then, arguably, imposed (in some sense) on the memory image activated by the word 'cyclamen'. This will vary to some extent across individuals: for some, the memory image evoked by 'cyclamen' may only be a nonspecific image of a flowering plant, which will be given more detailed content by its interaction with the moths image; for others, the memory image of the flower may be vivid and detailed, and the interest of the metaphor will be in how well the moth imagery meshes with and enhances that existing flower image.

The kinds of mental image just discussed are, as McGinn (2004, p. 128) puts it, "a type of sensory content of consciousness". I move on now to consider the relation between this (conscious) mental imagery and the widely discussed phenomenon of "perceptual simulation' in conceptual processing. The latter has been extensively investigated and discussed by Lawrence Just ${ }^{9}$

With regard to language processing, often cited behavioural experiments show that reading a text which implies a particular orientation of an object (e.g., hammering a nail into a wall versus into a floor) or a particular shape of an object (e.g., an eagle in a nest versus an eagle in the sky) significantly affects subsequent response times in tasks such as identifying a nail in one or other of the two implied orientations as a nail, or identifying an eagle with folded wings vs. one with spread wings as an eagle (see, e.g., Zwaan \& Madden, 2005). However, these experimental results are consistent with an explanation in purely amodal conceptual terms as well as in the favoured visual simulation terms, so they do not, by themselves, establish a key role for perceptual simulation in language comprehension. This is not the place to attempt any assessment of these different

\footnotetext{
9 An interesting development of the perceptual simulation view and its relevance for mental imagery is the strong 'embodiment' view of Gibbs \& Berg (2002), according to which there are important correspondences between mental imagery and embodied action. I can't pursue this here, but I think much of the ensuing discussion applies equally to this stronger version of grounded cognition.
} 
explanations of language comprehension or of the much wider debate about amodal versus multimodal conceptual knowledge (for discussion, see Mahon \& Caramazza, 2008;

Barsalou, 2008, 2016). What can't be disputed is the clear evidence from neuroscientific work using brain imaging techniques (specifically fMRI) that many of the modalityspecific areas of the brain that sustain ordinary sensory-perception and motor activity are activated during conceptual processing (e.g. in thinking about objects, performing mental categorisation, comprehending language). Again, it remains open whether this is intrinsic (so concepts simply are multimodal entities) or merely correlational (perhaps activation cascades rapidly from amodal conceptual areas to associated modality-specific areas, without the latter playing any constitutive role in conceptual processing) - see Mahon and Caramazza (2008) for discussion of the range of possible explanations.

The question now is what significance, if any, these 'perceptual simulation' activities in the brain have for the phenomenon of (conscious) mental imagery: are they wholly, partly, or not at all responsible for our mental imaging capacity? Intuitively, it might seem unlikely that the mechanisms or processes that support these two apparently strongly related activities would not overlap or be connected in some way. However, empirical work on (conscious) imagery and perceptual simulation by Pecher et al. (2009) seems to indicate a strong disconnect between the two, leading them to claim that, if there is any relation or overlap between them, it is rather minimal. They investigated the relationship between imagery and the 'modality-switch' effect, that is, the well-attested effect of a processing cost in property verification tasks if a target trial (e.g. apple-red) is preceded by a context trial from a different modality (e.g. airplane-noisy) rather than one from the same modality (e.g. diamond-sparkling). They found no correlation between this effect and individuals' imaging ability, where the latter was assessed by a range of performance measures that tapped both tendency to use imagery and vividness of imagery 
(in several different modalities). That is, whether an individual was a high or a low (conscious) imager made no difference to their performance in the task that measured the modality-switch effect. Pecher et al. (2009, p. 918) concluded that "perceptual simulation and imagery ability are not the same" and "[they] do not share much processing". However, they don't rule out the possibility that simulation is one of the components of imagery, pointing out that since simulations happen automatically and unconsciously, it may be that the final stages of the simulation process can and sometimes do reach awareness, at which point more effortful conscious imagery processing comes into play. They note that, while there are significant individual differences in ability to focus on and manipulate mental images, "because simulation is automatic, it contributes little variability to overall performance" (ibid, p. 918).

The conclusion that Pecher et al. reach regarding the relation between automatic perceptual simulation and conscious imagery is that, at most, there is just a small overlap between the two, namely, at the point at which the former reaches awareness (if and when it does). ${ }^{10}$ Their findings mesh with a growing consensus on the role of perceptual (and motor) simulation in language processing, which is that it is automatically activated by language and need not, but may, in its later stages, surface as phenomenologically salient mental imagery. For instance, based on results from a series of experiments (both behavioural and brain-imaging), Barsalou et al. (2008, p. 250) propose the following interaction between linguistic processes and perceptual simulations: “... simulations are often activated automatically and quickly (e.g. within 200 milliseconds of word onset) ... Although simulations may become active quickly, they may not dominate conscious

\footnotetext{
10 The main question that Pecher et al. (2009) were addressing was different from the one I am pursuing here (essentially its opposite). Along with many others working on 'grounded or embodied cognition', they start from the assumption that sensory-motor systems play a key role in conceptual knowledge, and their question is whether "conscious perceptual imagery is the mechanism that underlies mental representation" (ibid, p. 914). On the basis of their experimental results, they conclude that it is not: concepts rely on automatic activation of modality-specific systems independent of an individual's ability or tendency to use mental imagery.
} 
deliberate cognition immediately. ... Executive processing can focus on the linguistic system as its primary source of information for at least several seconds, before simulations begin to have effects on behaviour." They suggest that executive processing focuses on the information that the linguistic system can provide until that system stops being useful and then switches to the simulation system as an alternative source of information, an idea that would reconcile the fMRI evidence for fast activation of sensory-perceptual-motor areas of the brain with their own findings that the (amodal) linguistic system can dominate for several seconds. They argue that simulations represent deep conceptual information, providing more detailed informational content than linguistic forms alone. Along related lines, Louwerse and Jeuniaux (2008) maintain that, although some words trigger visual/motor imagery in certain circumstances, the efficiency of on-line language processing makes this a somewhat infrequent occurrence; others also suggest that 'embodied' representations are too slow and resource-consuming to be routinely generated as the outputs of comprehension (for a review of the arguments, see de Vega et al. (2008)). Distinct from the automatically activated unconscious perceptual simulation just discussed, is "mental imagery [which] typically results from deliberate attempts to construct conscious representations in working memory" (Barsalou, 2008, p. 619). This has been investigated intensively by Stephen Kosslyn and colleagues (for an overview, see Kosslyn et al., 2006). Typically, their experimental participants are instructed to recall or imagine an object or a scene, to scan it, possibly to rotate it (if it's an image of an object) or to move elements of it (if it's an image of a scene). The aims and results of the many experiments carried out do not matter here, but the point is that the evidence indicates that this is also a kind of perceptual simulation (Currie (1995) describes visual imagery as "off-line visual simulation"). Brain-imaging studies indicate overlap of some of the brain regions involved in ordinary on-line perception and in this kind of deliberate imaging, and 
testing the top-down visualising abilities of people with specific brain lesions that impair their perception supports the view that (visual) imagery is calling on many of the same capacities as (visual) perception (Farah, 1989; Kosslyn et al., 2006). Overall, then, it seems pretty clear that perception, automatic perceptual simulation, and deliberate imaging overlap in significant respects in the representations they produce and in the neural mechanisms that underlie them.

The conscious mental imagery that reportedly accompanies some metaphorical (and other) uses of language, which is the focus of this paper, is not identical to either the unconscious, automatically activated perceptual simulations, discussed by Barsalou, or to the deliberate task-driven generation of images, discussed by Kosslyn, although it has some of the features of both of them. As discussed above, the current state of the evidence and argument is that automatically activated sensorimotor simulation processes probably do not regularly play an active role in language comprehension. Nevertheless, there are some 'special' cases, those which enable or require slower, more effortful processing, where simulations of a more sustained and finer grain occur, and these may be consciously experienced by readers/hearers. Such conscious simulations then come under a degree of voluntary control, that is, available to some of the same top-down executive processes as the deliberate strategic cases of image generation, inspection, and transformation. The question at issue here, then, is whether metaphorically-used language, or at least some instances of metaphor, perhaps those that are novel, complex, creative and/or extended, could be such cases, where this kind of consciously available simulation (= imagery) plays a role in comprehension. This possibility is considered in the next section.

To sum up: the phenomenon of mental imagery, as it pertains to the concerns of this paper, has the following properties: 
1. It is conscious, so phenomenologically salient (as distinct from low-level sub-personal sensory-perceptual representations).

2. It often has direct counterparts in actual externally-caused perceptual experiences (visual, auditory, tactile, kinesthetic, etc.) and can be thought of as remembered or imagined perceptual experiences.

3. It may be voluntary (conjured up at will) or involuntary (as with, e.g., unwanted flashbacks or tunes that 'play' over in the mind). As accompaniments to language processing, images seem to be automatically activated by the very process of accessing words (specifically their encoded meanings), but once consciously available they come under a degree of voluntary control.

4. Mental imaging is productive (or creative), that is, even if it has a basis in automatic processes of sensory-perceptual simulation (re-enactment), it goes beyond mere simulation in that mental images can be imaginatively (re)constructed and combined with one another.

In the rest of the paper, I will continue to put the words 'image', 'imagery' and 'imagistic' in quotes when they are being used in the intuitive lay sense (e.g. in saying of the Cyclamen poem that it is highly 'imagistic') and use the phrase 'mental imagery' without quote marks when I intend to refer to those mental representations which are experienced as quasi-perceptual memories or imaginings with the properties just listed.

\section{Understanding metaphors: Pragmatics and the role of mental imagery}

The central question about the role of mental imagery in metaphor understanding was raised some time ago by Gibbs and Bogdonovitch (1999): “... whether the occurrence of 
mental imagery with metaphor is simply epiphenomenal to its comprehension or a key element in understanding its figurative meaning" (p. 39). Based on the results of an empirical study of readers' interpretations of a highly 'imagistic' poem, Free Union, by André Breton, they concluded that mental imagery is essential in understanding at least some metaphors, those that they (following Lakoff \& Turner, 1989) call 'image metaphors'. The poem is quite long, so I reproduce here just a few lines from it:

5. My wife whose hair is brush fire

My wife whose eyelashes are strokes in the handwriting of a child

Whose eyebrows are nests of swallows

With eyes that are purple armour and a magnetised needle.'

Gibbs and Bogdonovitch's expectation was that participants' interpretations of these metaphors would predominantly involve physical perceptible properties, reflecting the mapping of an image from the source domain (e.g. brush fire, child's handwriting) onto the target domain (e.g. hair, eyelashes), rather than what they call 'relational information', that is, general knowledge of a non-imagistic sort about the source domain, e.g. that brush fires are hard to control, they spread quickly, they are exciting and dangerous, etc.

In their first study, they asked participants (20 undergrad students) to provide verbal reports of their interpretations of lines of the poem, and then organised the responses into seven different categories (ibid, p. 40). They found that most of the responses $(60 \%)$ fell in the category of what they called 'physical transfer', that is, they described physical features of the metaphor target (hair, eyelashes, etc.) which were based 
on projection of the physical features of the source (brush fire, child's handwriting, etc.). An example for the line about hair was: 'The wife's hair is flaming red in colour and wild and untamed like a bush fire', and for the line about her eye-lashes 'Her eye-lashes are thick, long as if they were single strokes of a child's writing or painting'. Responses falling in the category of transfer of 'relational information' were quite rare (8\%), e.g. for the 'eyelashes/handwriting' case, 'Her eyelashes are original, pure, and innocent'. So the results seemed to support Gibbs and Bogdonovitch's hypothesis.

They followed up with two further studies aimed at distinguishing more clearly the information in visual images from general propositional knowledge. In brief: one group of participants were asked to describe their 'visual images' for individual target and source domains taken from the Breton poem, while a different group had to describe the 'main characteristics' of those domains. The responses of the two groups were mostly quite distinct. For instance, given the phrase 'nests of swallows', the 'imaging' group gave descriptions of what nests are made of (twigs, straw, etc.), where they are located (in trees or rafters of barns), and what is found in them (eggs, birds). The group instructed to describe characteristics tended to produce comments about the function of nests (e.g., birthplace, shelter, security), evaluative remarks (e.g., cute, unsanitary), as well as mentioning a few 'image-like' features, but without the concrete detail produced by the visual imagers (ibid, p. 42). The responses of the two groups were then compared with the metaphor interpretations given in the first study and it was found that a significantly higher percentage of the descriptions of the imaging group than those of the non-imaging group corresponded to the metaphor interpretations (59\% versus $12 \%)$. Gibbs and Bogdonovich concluded that the interpretations of these metaphors arise from readers mapping of mental images from the metaphor's source domain (e.g., brush fire) onto the target domain (e.g., woman's hair) “to better structure and give even greater imagistic 
detail" to the target domain (ibid, p. 43). In short, their answer to the question posed is that mental images are not merely epiphenomenal, but play an essential role in understanding these metaphors.

However, it could be argued by a sceptic about the role of mental imagery in metaphor understanding (even in cases of 'image' metaphors), that our store of propositional knowledge about brush fires and about birds' nests includes information about their physical attributes (e.g., that brush fires light up the landscape with a mass of red and yellow leaping flames; that birds' nests are made from twigs and straw, woven together in a bowl shape, etc.) as well as relational information. Given the topic of each metaphor, a woman's hair or her eye-brows, and the wider context of the poem (a lengthy description of different parts of her body), this encyclopaedic knowledge about (some of) the physical attributes of the thing denoted by the metaphor vehicle (brush fire, nests of swallows) would be more highly activated than irrelevant information about functional and relational properties of these entities. Such propositional information would then provide the contextual assumptions from which relevant implications (implicatures) are derived: her hair is long and red, wild and tangled, shimmers brightly, etc. On this sort of account, then, mental images are not playing any instrumental role in the derivation of the intended effects of the metaphor. This, in outline, is how a standard relevance-theoretic account of such cases might go (see Sperber \& Wilson, 2008; Wilson \& Carston, 2008). ${ }^{11}$

So, while I find the account given by Gibbs and Bogdonovitch very appealing and tend to think that mental images can sometimes play a significant role in these and other cases of metaphor (see below), I don't think the case has yet been made against the view that these images are anything more an epiphenomenon or incidental side-effect, with all

11 As an anonymous referee pointed out, it is possible that my objection rests on the specifics of the examples discussed by Gibbs and Bogdonovitch (1999). Other cases of metaphor, those involving so-called 'emergent properties', need to be shown to be susceptible to the same amodal propositional account (see Wilson and Carston (2008) for discussion of emergent properties and Green (2017) for cases of what he calls 'image-demanding' metaphors). 
the real work of understanding being done by standard pragmatic processes of inference on conceptual/propositional representations. After all, it's these kinds of representations (sentences in the language of thought) that are the mental equivalents of the verbal reports given by the participants in the experiments (the propositions they expressed with their utterances). It is difficult, of course, to find a more direct way (one not mediated by verbal reports of metaphor interpretations) to detect the presence or absence of mental imagery in the mind/brain of the person understanding a metaphor, let alone to tell whether the imagery of the vehicle domain is being mapped onto the target domain.

There has been some neurocognitive work investigating the extent to which sensory-perceptual (and motor) areas of the brain are activated during metaphor processing. Marcel Just and colleagues conducted fMRI studies that compared areas of brain activation during reading comprehension of two groups of verbal metaphors: familiar/frozen cases and unfamiliar/novel cases, as exemplified by the following, where the first two sentences provided the context for the metaphorical utterance in the third:

6. Frozen metaphor:

Mary got straight A's on her report card.

Her parents were proud of her.

They said, "You are as sharp as a razor"

Novel metaphor:

It was Judy's first time on an airplane.

Her mom let her have the window seat.

Judy said, "We're surrounded by great white mushrooms" 
Summing up the results, Just (2008, p. 80) says: "During the comprehension of a frozen metaphor, the same language processing areas are active as in normal [= literal $(\mathrm{RC})]$ reading ... However, it is the contrast with novel metaphors that is important here. The novel metaphors evoked parietal activation ..., suggesting that visual imagery processes were being used to instantiate and/or interpret the novel metaphors. The novel metaphors were generally visual in nature, such as a metaphor comparing a winding road to a ribbon. These results demonstrate the selective use of imagery in metaphor comprehension, suggesting that perceptual representations are used in the comprehension of novel, but not frozen, metaphors. It may be that the mappings between domains that are needed in novel metaphor comprehension ... are often mediated through visual-spatial representations. ... In this view, embodiment occurs only for those types of metaphors that require it for their appropriate comprehension."

In another fMRI study, of the processing of what they call 'sensory-motor' metaphors, Desai et al. (2011) got rather similar results with regard to the difference between familiar and unfamiliar metaphors. They concluded that while sensory-motor areas of the cortex are activated to some extent in understanding all metaphorically used action words (e.g. 'grasp an idea', 'grab life by the throat'), 'the involvement of sensorymotor systems in metaphor understanding changes through a gradual abstraction process whereby relatively detailed simulations are used for understanding unfamiliar metaphors, and these simulations become less detailed and involve only secondary motor regions as familiarity increases" (ibid, p. 2376). ${ }^{12}$

We can't be certain that any of the sensory-motor simulations discussed by these authors constitutes the kind of (conscious) imagery that is at stake in this paper.

\footnotetext{
12 As well as activation of sensory-motor systems, Desai et al. (2011) found that metaphorical sentences activated brain regions associated with abstract (non-imagistic) language processing and concluded that "action metaphor understanding is not completely based on sensory-motor simulations but relies also on abstract lexical semantic codes" (ibid, p. 2376).
} 
Nevertheless, it seems reasonable to expect that novel metaphors would take longer and be more costly to comprehend than familiar ones and there is accumulating experimental evidence that this is indeed the case, even when the metaphor is appropriately contextualised (Giora, 1999, 2003; Bowdle \& Gentner, 2005; Arzouan et al., 2007; Lai et al., 2009). Thus, novel metaphors are an instance of the kind of 'special' language processing situation discussed in the previous section, in that they involve more effortful, deeper and slower processing than most ordinary instances of comprehension, and have been found to correlate with sensory-perceptual simulations of a more sustained and finer grain, which may be experienced as such by readers/hearers. This seems all the more likely to be the case for the 'image' metaphors discussed in section 2 (e.g., 'They are white moths / with wings / lifted / over a dark water / in act to fly / ...'), which are considerably more creative and sustained, hence more demanding of processing effort, than the kinds of examples used in any of the experiments. Nevertheless, it is a further claim, and one which has yet to be substantiated, that the simulations (images) are being actively used in understanding the metaphor, as is suggested by Just (2008) in the quote above. That is, although they are occurring, although they may be phenomenologically salient, perhaps even a source of pleasure for the reader/audience, still they may not be implicated in 'understanding' the metaphor, that is, in grasping what the author of the metaphor intended by it.

Let me turn now to pragmatic accounts of metaphor, by which I mean those accounts which see metaphor as one way, among many others, in which language is employed by speakers/writers in order to fulfil their communicative intention and which, like all other uses, are interpreted by hearers/readers in accordance with the presumption that they will gain a worthwhile return of cognitive effects for their investment of attention and processing effort. Of course, utterances may result in information transmission and 
other kinds of cognitive impact that go well beyond anything communicatively intended by the speaker/writer; for instance, they may reveal information about a speaker's social class or sex or political affiliations or state of health; they may (unintentionally) cause the audience to feel uneasy, envious, superior, sympathetic, and so on. As Colston (2015) points out, there is a wide range of 'pragmatic effects' (on his use of this term) beyond those communicatively intended by a speaker/writer, including what he calls sociocognitive effects, multimodal effects, and cognitive side-effects. Of particular interest to this paper is the category of cognitive side-effects, which Colston characterises as effects that arise from perceptual and cognitive processes that are running in parallel with language processing proper but can 'leak into and affect meaning' (ibid, p. 217); below I will suggest that mental imagery may be such a case.

However, the focus of inferential pragmatic theories is 'ostensive communication', that is, the overtly intended sharing of information and experience which achieves its intended effects largely through the recipient's recognition that they are intended (Grice, 1969; Sperber \& Wilson, 2002). It is this kind of communication that enables a measure of shared understanding of the world (a mutual cognitive environment), which is arguably the basis for much of human social-cultural life. On Grice's various versions of the intention with which a speaker produces an utterance (known as a 'meaning intention', or m-intention), the kind of m-intended effect is restricted to a propositional attitude such as a belief (the speaker/writer makes overt her intention that the audience should come to hold a particular belief or beliefs and should come to do so, at least in part, through recognition of that intention). On the relevance-theoretic definition of a communicative intention, a speaker makes overt ('mutually manifest') her intention to make an array of propositions manifest or more manifest to her addressee, where "a proposition is manifest to an individual at a given time to the extent that he is likely, to some positive degree, to 
entertain it and accept it as true" (Sperber \& Wilson, 2015, p. 134). The two accounts differ in some significant respects, ${ }^{13}$ but they both assume that what is overtly communicated is something propositional (truth-evaluable) and thus they exclude images (or their contents) from falling in the domain of overt communication. As is made clear in Sperber \& Wilson (2015), mental images, like percepts (and the objects in the world that cause them), are not the kind of entity that can be made manifest. ${ }^{14}$

In the case of the conscious imagery that metaphorical uses of language reportedly prompt, there is no temptation to attempt a redefinition of 'manifestness' such that it could apply to the contents of images as well as to propositions. The image evoked by a metaphor vehicle, e.g. the image of moths in the case of the cyclamen poem in (1), of the foldaway construction of canvas and struts in the 'heron' metaphor in (2), or of the red face of a farmer in (3), are not, in and of themselves, contents that the writer intends the audience to add to his understanding (his mental model) of the world. Nor is the superimposition of that image on (an image of) the metaphor topic, e.g. an image of the wings of white moths blended with an image of the petals of the flowers, or the transformation of an image of a heron by imposing on it an image schema of a canvasand-struts construction, or, to cite Davidson (1978) discussing the dead metaphor 'He was burned up': 'When the metaphor was active, we would have pictured fire in the eyes or smoke coming out of the ears.' (ibid, p. 38) ${ }^{15}$ None of these is an accurate representation of anything in the world, but is rather a construct of the imagination (representing some

\footnotetext{
13 The relevance-theoretic account of ostensive communication goes well beyond Grice's notion of 'speaker meaning' to encompass cases of 'weak' communication, whether verbal or non-verbal, including the communication of impressions and other less than fully determinate 'information' (see, in particular, Sperber \& Wilson, 2015).

14 However, a communicator can make particular objects, percepts, and images more salient (i.e., more noticeable) to an audience and so increase the likelihood that they will be used as a source of input to the comprehension process.

15 Here I am deliberately leaving it open what sort of image (whether a specific memory image or a more abstract image schema) might be involved and what sort of image combination might occur (blending, fusion, superimposition, or a rapid shifting back and forth between images (see Gleason, 2009).
} 
non-actual, even fantastical, world), and we would go seriously astray if we were to attempt to integrate these into our representation of the world, consisting of propositional knowledge and memory images (grounded in perception).

Let's accept that speakers do not communicate the contents of images and thus images are not among the mental representations that constitute the output of processes of comprehension or interpretation of utterances/texts, the goal of which is to recover the intended interpretation. However, it doesn't follow from this that images are not evoked or activated by some uses of language, or that skilful speakers and writers, who are aware of this, do not aim to achieve imagistic effects in the image-receptive hearer/reader. As discussed earlier, individual differences notwithstanding, there are many people who report experiencing mental images when reading the metaphors discussed above, and there is now quite a lot of neuroscientific evidence that perceptual simulations take place in the brain during the processing of metaphor (and other kinds of language use), some of which, especially those activated by novel metaphors, are quite vivid and detailed. These images, especially for those willing and able to sustain them, inspect them and manipulate them (Kosslyn et al., 2006), are a genuine effect of these uses of language, and one which is often the most memorable and powerful effect of a metaphor. Recall in this regard, Crisp's (1996) remark, cited in section 2, that what is arousing about the metaphorical simile in Hulme's poem Autumn is the experience of projecting the image of a farmer's red face onto the image of the moon, and not the banal proposition that 'the moon was roundish and reddish', which is no doubt one of the propositions communicated by the simile. The flat-footed nature of attempts to list propositions communicated by a moderately creative metaphor has often been noted, as has the impossibility of adequate paraphrase (see, e.g., Camp, 2006, Sperber \& Wilson, 2015). In cases like this, it is the information-rich and 
sometimes startling mental imagery that has the most impact on us and not the propositions communicated. ${ }^{16}$

Is that it, then? Is it the case that all we can say with any certainty is that imagery is an interesting/enlivening/pleasing by-product of the way language and memory work? This would be a non-negligible effect, one that is worth developing through careful crafting of a speech or text. However, working within the relevance-theoretic (RT) account of communication, I would like to consider the possibility of a further role that images might have, albeit one that does not have the status of an essential role in language comprehension/interpretation.

An important aspect of the RT framework is the idea that thoughts/propositions vary in the strength with which they are communicated (Sperber \& Wilson, 1986/95, 2008, 2015). A speaker/writer may have in mind a specific implication on which the relevance of her utterance depends and a strong intention that the hearer/reader should derive it, in which case, it is strongly communicated; at the other extreme, "she may have in mind a vague range of possible interpretations with roughly similar import, any subset of which would contribute to the relevance of her utterance, and a weak intention, for any of the implications in that range, that the hearer/reader should derive it; these are weak implicatures" (Sperber \& Wilson, 2008, p. 99). A speaker/writer's intentions may fall anywhere between these two extremes. In the case of novel, creative and/or sustained metaphors, such as those discussed in this paper, relevance is achieved through the communication of a wide array of weak implicatures, variable subsets of which are recovered by different readers, who must therefore take some responsibility for the particular interpretation that they derive. There is, thus, considerable leeway in the 'space'

${ }^{16}$ Based on extensive empirical work on mental images and the 'imagery values' of different words and phrases, Allan Paivio has highlighted the information density of images (as compared with sentential mental codes) and the memorableness of images (their well attested mnemonic value), both of which bear directly on the cognitive impact which metaphors (and other uses of language) that enable sustained mental imaging can have on us (see, e.g., Paivo, 1983; Paivio \& Walsh, 1993). 
of implicatures/implications that may be derived by different hearers/readers, all of whom can nonetheless count as having interpreted the utterance/text appropriately (i.e., as communicatively intended). ${ }^{17}$

Where do these weakly implicated thoughts/propositions come from? Certainly some are inferred from propositional information stored in encyclopaedic entries associated with the concepts encoded by the language used (e.g. the concepts: WHITE MOTHS WITH WINGS LIFTED, CONSTRUCTION OF STRUTS AND CANVAS, WHEEZING BAGPIPE, etc.). However, as Sperber and Wilson (2015) emphasise, there are many ways of making propositions manifest, including drawing someone's attention to an object or scene in the world by pointing or using gestures (e.g., an ostensive sigh or sniff, a deliberate facial expression), or making a demonstrative utterance (e.g., 'Listen to this', 'Look at that'). As noted in section 2, these are ways of getting an addressee to draw on their own perceptual experience as a means of recovering propositions/thoughts that fall within the speaker's communicative intention. My suggestion is that some verbal metaphors (and some other uses of language) can achieve something similar by activating mental images and sustaining them above the threshold of consciousness. These images increase the degree to which certain thoughts/propositions are manifest to readers/hearers, propositions which may be used in deriving (weakly communicated) implications, which contribute to the relevance of the utterance/text. This hypothesis could explain the findings of Gibbs and Bogdonovitch (1999) above. For instance, if a mental image of a brush fire is activated by reading 'My wife whose hair is brush fire' (as the reports of individual readers, backed up by neuroscientific findings, suggest), then at least some aspects of the (propositional) interpretations reached, e.g. her hair was red and gold, tangled and wild, etc., could have

\footnotetext{
17 This account in terms of a dense array of weakly communicated thoughts might be one way of instantiating Ortony's (1975) claim, discussed in section 2 above, that metaphor can enable the transfer of 'large chunks' of information and so bring about a more vivid 'particularised' understanding of the experience the speaker is trying to communicate.
} 
been made manifest by the mental imagery activated. We can surmise that, as well as being a source of pleasure in themselves, mental images may play an instrumental role in the interpretation process, without thereby making any commitment to images being essential components in the understanding of these metaphors.

Two (related) objections to this idea might be raised: (a) mental images are too variable and idiosyncratic for this to be a reliable way of recovering speaker intended content, and (b) as noted, images are informationally dense, so even if they were stable across individuals, there would be a further issue concerning how the individual selects among the indefinite range of propositions made manifest to him. To respond fully to the first objection, we would need to know much more about the nature of the mental images evoked (including how detailed or schematic they are), but a strong constraint on the mental images activated is provided by the language itself - this is linguistically guided/constrained imaging, more in line with Kosslyn's verbal instructions for visualising than with the largely unconstrained imaging of daydreaming or fantasising. Furthermore, as just discussed, in the case of Sperber and Wilson's weakly communicated implications, there is a fair bit of variation with regard to the thoughts that can comprise an acceptable interpretation, that is, one that falls within the speaker/writer's communicative intention. As regards the second possible objection, there is an immediate answer that comes directly from the core of any pragmatic theory: all utterance/text interpretation is strongly constrained by hearer/reader's expectations of relevance (and/or informativeness, and/or coherence, etc., for those working in different frameworks from RT). As with the propositional encyclopaedic information activated by the concepts accessed through linguistic decoding, so with the propositions made manifest by activated mental images: they are subject to standard processes of selection, governed by how well 
they meet expectations based on the prevailing presumption of 'optimal relevance' (for details, see Sperber \& Wilson, 2008). ${ }^{18}$

On this account of mental images in the processing of metaphors, there is no sharp distinction between their roles in what the conceptual metaphor theorists call 'image' metaphors, on the one hand, and instances of 'conceptual' metaphors, on the other (Lakoff \& Turner, 1989; Gibbs, 1994). On their view, 'image' metaphors involve a mapping of mental images from one concrete/physical domain onto another concrete/physical domain, as in examples (1)-(2) and (4)-(5) above. Most ordinary verbal metaphors, however, are taken to be linguistic manifestations of conceptual metaphors, which involve the mapping of conceptual information associated with a concrete domain onto an abstract domain that can only be understood in terms of the concrete domain (e.g., LIFE IS A JOURNEY, PSYCHOLOGICAL STATES ARE PHYSICAL STATES, THE MIND IS A CONTAINER, etc.). These theorists talk of 'image' metaphors as involving novel, one-shot mappings between mental images, while conventional verbal metaphors reflect familiar robust mappings between conceptual domains (Gibbs, 1994, pp. 258-260). On the account given here, where mental images are cognitive by-products, albeit often vivid and impactful, and sometimes instrumental in giving access to propositional implications, there is no reason to suppose that these effects don't occur across the full range of novel, creative and/or poetic metaphors. So, in the following three cases, the metaphor topic/target ('life', 'depression', 'memory') is as abstract as any discussed by the conceptual metaphor theorists and yet the experience of mental images that the metaphor vehicle activates is not obviously any less vivid than it is in the earlier cases:

\footnotetext{
18 A reminder of the relevance-theoretic comprehension procedure which applies to the interpretation of all acts of ostensive communicative: (a) Follow a path of least effort in constructing an interpretation (including the resolution of ambiguities and referential indeterminacies, the supplying of contextual assumptions, the inferring of implicatures, etc.); (b) Stop when your expectations of relevance are satisfied (Sperber \& Wilson, 2002).
} 
7. Life's but a walking shadow, a poor player

That struts and frets his hour upon the stage

And then is heard no more: it is a tale

Told by an idiot, full of sound and fury,

Signifying nothing.

(W. Shakespeare, 1623. Macbeth V. v. 11. 24-30)

8. Depression, in Karla's experience, was a dull, inert thing - a toad that squatted wetly on your head until it finally gathered the energy to slither off.

(Z. Heller, 2008. The Believers, p.263)

9. Memory is a crazy woman that hoards colored rags and throws away food.

(A. O’Malley, 1920.)

As with the earlier examples, the mental images evoked may be the source of manifest propositions that readers can use in deriving an array of (weak) implicatures about the nature of life, depression, or memory.

\section{Summing up}

The central question discussed in this paper is what role, if any, (conscious) mental imagery plays in the understanding of verbal metaphors. The alternatives we started with were that either it plays an essential role in metaphor comprehension or it is merely an 
epiphenomenon, having no effect on the process at all. However, these two positions do not exhaust the options and the final position I take lies between them: imagery does not play an essential role, but it can play a significant tangential role.

The behavioural evidence, discussed in the preceding section, in which participants reported on their interpretations of 'image' metaphors, seems explainable in amodal propositional terms. The neuroscientific evidence, which shows different degrees of activation of various sensory-motor areas of the brain depending on the degree of familiarity of a metaphor, is primarily focused on unconscious (sub-personal) processes, although in cases of novel metaphor these simulations may become consciously available. On the basis of the current state of the evidence, then, it looks as if the experience of mental imagery during the comprehension of a metaphor is probably a by-product or sideeffect of other processes, an outcome of such factors as the novelty, creativity and extendedness of the metaphor and, following from that, the time/effort involved in reaching an interpretation. However, even if (conscious) mental imagery is (merely) a cognitive side-effect of standard linguistic and inferential pragmatic processes of verbal understanding, it can be of considerable significance, in at least the following respects:

a. It may be the most powerful and/or memorable effect a metaphor has on its audience.

b. It may be an effect the author sets out to achieve and expects/wants the audience to experience.

c. It may provide a valuable input for the derivation of the cognitive implications that fall within the speaker/writer's communicative intention. 


\section{Acknowledgements}

I am grateful to Ruth Filik and Rachel Giora, the editors of this special issue on figurative language, for their support and considerable patience during the process of writing this paper. I have benefited from relevant discussions with Deirdre Wilson, Terence Cave, Catherine Wearing and Lewis Pollock, and from the thoughtful comments of an anonymous referee. Finally, my heartfelt gratitude to Rachel Giora for beautiful images and kind words when they were most needed.

\section{References}

Arzouan, Y., Goldstein, A., \& Faust, M. (2007). Brainwaves are stethoscopes: ERP correlates of novel metaphor comprehension. Brain Research, 1160, 69-81.

Barsalou, L. (1999). Perceptual symbol systems. Behavioral and Brain Sciences, 22, 577660.

Barsalou, L. (2008). Grounded cognition. Annual Review of Psychology, 59, 617-45.

Barsalou, L., Simmons, W., Barbey, A., \& Wilson, C. (2003). Grounding conceptual knowledge in modality-specific systems. Trends in Cognitive Sciences, 7(2), 8491.

Barsalou, L., Santos, A., Simmons, W., \& Wilson, C. (2008). Language and simulation in conceptual processing. In M. de Vega, A. Glenberg, \& A. Graesser (Eds.), Symbols and embodiment (pp. 245-284). Oxford UK: Oxford University Press. 
Barsalou, L.W. (2016). On staying grounded and avoiding Quixotic dead ends. Psychonomic Bulletin \& Review, 23, 1122-1142.

Bermúdez, J. \& Cahen, A. (2015). Nonconceptual mental content. In E. N. Zalta (Ed.), The Stanford Encyclopedia of Philosophy (Fall 2015 Edition).

$\mathrm{URL}=<$ https://plato.stanford.edu/archives/fall2015/entries/contentnonconceptual/>.

Bowdle, B., \& Gentner, D. (2005). The career of metaphor. Psychological Review, 112(1), 193-216.

Camp, E. (2006). Metaphor and that certain 'je ne sais quoi'. Philosophical Studies, 129, $1-25$.

Camp, E. (2008). Showing, telling and seeing: Metaphor and 'poetic' language. Baltic International Yearbook of Cognition, Logic and Communication, 3, 1-24.

Carston, R. (2002). Thoughts and utterances: The pragmatics of explicit communication. Oxford, UK: Blackwell.

Carston, R. (2010). Metaphor: ad hoc concepts, literal meaning and mental images. Proceedings of the Aristotelian Society, 110(3), 295-321.

Carston, R., \& Wearing, C. (2011). Metaphor, hyperbole and simile: A pragmatic approach. Language and Cognition, 3(2), 283-312.

Cave, T. (2016). Thinking with literature. Oxford, UK: Oxford University Press.

Colston, H. (2015). Using figurative language. Cambridge, UK: Cambridge University Press.

Crisp, P. (1996). Imagism's metaphors - a test case. Language and Literature, 5(2), 7992.

Currie, G. (1995). Visual imagery as the simulation of vision. Mind and Language, 10, 2544. 
Currie, G., \& Ravenscroft, I. (2002). Recreative minds. Oxford, UK: Oxford University Press.

Davidson, D. (1978). What metaphors mean. Critical Inquiry, 5: 31-47. Reprinted in D. Davidson 1984. Inquiries into truth and interpretation (pp. 245-264). Oxford, UK: Oxford University Press.

Desai, R., Binder, J., Conant, L., Mano, Q., \& Seidenberg, M. (2011).The neural career of sensory-motor metaphors. Journal of Cognitive Neuroscience, 23(9), 2376-2386.

de Vega, M., Graesser, A., \& Glenberg, A. (2008). Reflecting on the debate. In M. de Vega, A. Glenberg, \& A. Graesser (Eds.), Symbols and embodiment (pp. 397-440). Oxford UK: Oxford University Press.

Fainsilber, L., \& Ortony, A. (1987). Metaphor production in the description of emotional states. Metaphor and Symbolic Activity, 2(4), 239-250.

Farah, M. (1989). The neural basis of mental imagery. Trends in Neurosciences, 12(10), 395-399.

Fodor, J. (1983). The modularity of mind. Cambridge, MA: MIT Press.

Gibbs, R. (1994). The poetics of mind: Figurative thought, language, and understanding. New York, NY: Cambridge University Press.

Gibbs, R., \& Berg, E. (2002). Mental imagery and embodied activity. Journal of Mental Imagery, 26, 1030.

Gibbs, R., \& Bogdonovich, J. (1999). Mental imagery in interpreting poetic metaphor. Metaphor and Symbol, 14(1), 37-44.

Giora, R. (1999). On the priority of salient meanings: studies of literal and figurative language. Journal of Pragmatics, 31, 919-929.

Giora, R. (2003). On our mind: Salience, context, and figurative language. New York, NY: Oxford University Press. 
Gleason, D. (2009). The visual experience of image metaphor: Cognitive insights into Imagist figures. Poetics Today, 30(3), 423-470.

Glucksberg, S. (2001). Understanding figurative language. Oxford, UK and New York, NY: Oxford University Press.

Green, M. (2017). Imagery, expression, and metaphor. Philosophical Studies, 174, 33-46.

Grice, H. P. (1969). Utterer's meaning and intentions. Philosophical Review 78, 47-77. Reprinted in H. P. Grice (1989). Studies in the way of words (pp. 86-116). Cambridge MA: Harvard University Press.

Grice, H. P. (1975). Logic and conversation. In P. Cole \& J. Morgan (Eds.), Syntax and semantics 3: Speech acts (pp. 41-58). New York, NY: Academic Press. Reprinted in H. P. Grice (1989). Studies in the way of words (pp. 22-40). Cambridge MA: Harvard University Press.

Heller, Z. (2008). The believers. London, UK: Penguin.

Hulme, T. E. (1909). Poems. Poets' Club Anthology. London, UK: The Poets' Club Press. Hulme, T. E. (1936). Speculations, $2^{\text {nd }}$ ed., edited by H. Read. London, UK: Kegan Paul. Just, M. A. (2008). What brain imaging can tell us about embodied meaning. In M. de Vega, A. Glenberg, \& A. Graesser (Eds.), Symbols and embodiment (pp. 75-84). Oxford UK: Oxford University Press.

Kosslyn, S., Thompson, W., \& Ganis, G. (2006). The case for mental imagery. New York, NY: Oxford University Press.

Lai, V., Curran T., \& Menn, L. (2009). Comprehending conventional and novel metaphors: an ERP study. Brain Research, 1284, 145-55.

Lakoff, G., \& Turner, M. (1989). More than cool reason: A field guide to poetic metaphor. Chicago, IL: The University of Chicago Press. 
Louwerse, M., \& Jeuniaux, P. (2008). Language comprehension is both embodied and symbolic. In M. de Vega, A. Glenberg, \& A. Graesser (Eds.), Symbols and embodiment (pp. 309-326). Oxford UK: Oxford University Press.

Macfarlane, R. (2013). The old ways: A journey on foot. London, UK: Penguin Books.

McGinn, C. (2004). Mindsight. Cambridge, MA: Harvard University Press.

Mahon, B., \& Caramazza, A. (2008). A critical look at the embodied cognition hypothesis and a new proposal for grounding conceptual content. Journal of Physiology, 102, $59-70$.

Nanay, B. (2015). Perceptual content and the content of mental imagery. Philosophical Studies, 172, 1723-1736.

O’Malley, A. (1920). Keystones of thought. New York, NY: Devin-Adair.

Ortony, A. (1975). Why metaphors are necessary and not just nice. Educational Theory, $25,45-53$.

Paivio, A. (1983). The mind's eye in arts and science. Poetics, 12, 1-18.

Paivio, A., \& Walsh, M. (1993). Psychological processes in metaphor comprehension and memory. In A. Ortony (Ed.), Metaphor and thought, $2^{\text {nd }}$ ed. (pp. 307-328). Cambridge, UK: Cambridge University Press.

Pecher, D., Van Dantzig, S., \& Schifferstein, H. (2009). Concepts are not represented by conscious imagery. Psychonomic Bulletin \& Review, 16(5), 914-919.

Pound, E. (1970) [1914]. Vorticism. In E. Pound, Gaudier-Brzeska: A memoir (pp. 81-94). New York, NY: New Directions.

Richards, I.A. (1936/95). The philosophy of rhetoric. Oxford, UK: Oxford University Press.

Sadoski, M., \& Paivio, A. (2001). Imagery and text. Mahwah, NJ: Lawrence Erlbaum. 
Searle, J. (1979). Metaphor. In J. Searle, Expression and meaning (pp. 76-116).

Cambridge UK, Cambridge University Press.

Searle, J. (1980). The background of meaning. In J. Searle, F. Keifer \& M. Bierwisch (Eds.), Speech act theory and pragmatics (pp. 221-232). Dordrecht, The Netherlands: Reidel.

Shakespeare, W. (1623). Macbeth. Edition published (1992) in C. Watts (Ed.), Wordsworth Classics. UK: Wordsworth Editions Ltd.

Sperber, D., \& Wilson, D. (1986/95). Relevance: Communication and cognition. Oxford, UK: Blackwell. Second edition with new Preface 1995.

Sperber, D., \& Wilson, D. (2002). Pragmatics, modularity and mindreading. Mind \& Language, 17, 3-23.

Sperber, D., \& Wilson, D. (2008). A deflationary account of metaphors. In R. Gibbs (Ed.), The Cambridge handbook of metaphor and thought (pp. 84-105). Cambridge, UK: Cambridge University Press.

Sperber, D., \& Wilson, D. (2015). Beyond speaker's meaning. Croatian Journal of Philosophy, $X V(44), 117-149$.

Thomas, R. S. (1946). The stones of the field. Carmarthen, South Wales, UK: The Druid Press. Reprinted in R. S. Thomas (1993). Collected poems: 1945-1990 R.S. Thomas. London, UK: J. N. Dent.

Watson, J. B. (1928). The ways of behaviourism. New York: Harper.

Wilson, D. (in press). Relevance theory and literary interpretation. In T. Cave \& D. Wilson (Eds.), Reading beyond the code: Literature and relevance theory. Oxford, UK: Oxford University Press. 
Wilson, D., \& Carston, R. (2007). A unitary approach to lexical pragmatics: Relevance, inference and ad hoc concepts. In N. Burton-Roberts (Ed.), Pragmatics (pp. 230259). Basingstoke UK: Palgrave Macmillan.

Wilson, D., \& Carston, R. (2008). Metaphor and the 'emergent property’ problem: A relevance-theoretic treatment. The Baltic International Yearbook of Cognition, Logic and Communication, 3, 1-40.

Zwaan, R. A., \& Madden, C. J. (2005). Embodied sentence comprehension. In D. Pecher \& R. Zwaan (Eds.), Grounding cognition: The role of perception and action in memory, language, and thought (pp. 224-245). New York, NY: Cambridge University Press. 